\title{
Application of an Educational Resource for Parents of Seven-Year-Old Children Diagnosed with Developmental Coordination Disorder
}

\author{
Patrícia Carla de Souza Della Barba \\ Department of Occupational Therapy, Federal University of São Carlos, São Paulo, Brazil \\ Email: patriciabarba@ufscar.br
}

Received 7 December 2014; accepted 10 January 2015; published 16 January 2015

Academic Editor: Arturo Díaz Suárez, University of Murcia, Spain

Copyright (C) 2015 by author and Scientific Research Publishing Inc. This work is licensed under the Creative Commons Attribution International License (CC BY). http://creativecommons.org/licenses/by/4.0/

c) (i) Open Access

\begin{abstract}
The present study aims to discuss the application of educational resource "Children with Developmental Coordination Disorder: at Home, at School and in the Community" (Missiuna, Rivard, \& Pollock, 2011) for parents of seven-year-old children of a public school in a Brazilian city. The booklet aims to help parents and teachers identify and manage school-aged children with developmental coordination disorder (DCD). Methods: The contents of the booklet were used in a group of four parents of children previously identified with DCD in the school environment using a workshop. Results: The meetings of the parents were oriented to the characterization of the disorder. The activities helped parents understand the difficulties of their children. Conclusion: In this study it was found that the use of the educational resources together with games proved to be an important approach to working with parents of children with DCD. However, it is important to expand the number of participants in future studies.
\end{abstract}

\section{Keywords}

Educational Resources, Parents, Developmental Coordination Disorder (DCD), School

\section{Introduction}

The early detection of childhood developmental disorders is considered essential to prevent future problems in

How to cite this paper: de Souza Della Barba, P. C. (2015). Application of an Educational Resource for Parents of Seven-Year-Old Children Diagnosed with Developmental Coordination Disorder. Advances in Physical Education, 5, 1-6. 
life, since a diagnosis early enough to implement intervention activities increases their chances of reaching their full potential and living normally among their peers. The Developmental Coordination Disorder (DCD) occurs when there is delayed development of motor skills or difficulty coordinating movements, not justified by general medical conditions or mental retardation, resulting in poor academic performance, school and daily activities (Missiuna, Rivard, \& Pollock, 2011). With prevalence estimates of approximately 6\% (APA, 2013), Developmental Coordination Disorder (DCD) is a condition that deserves special attention because of its impact on school activities and daily life. It may also be associated with other disorders such as learning disabilities and social and emotional problems, primarily attention deficit hyperactivity disorder (Missiuna et al., 2007; Polatajko \& Cantin, 2006; Pereira, Araújo, \& Mattos, 2005).

The diagnosis should be made as early as possible, since children with DCD experience failure and frustration in their academic and daily lives are commonly labeled as lazy, uncoordinated, unmotivated, or clumsy (Araujo, 2010).

The school environment is most promising for the identification of children with DCD. The daily school routine demands virtually the entire spectrum of motor skills and has the advantage of housing a privileged observer, the teacher (Silva et al., 2006). Along with disorder identification, it is also important to develop strategies with parents and teachers to help children with DCD manage success in their daily activities and promote their inclusion in the school and community.

Consequently, Missiuna, Rivard, \& Pollock (2011) wrote the booklet entitled "Children with Developmental Coordination Disorder: At Home, at School and in the Community" that was translated to Portuguese by Magalhães and directed to parents and teachers to help them identify the signs of DCD and manage their children's difficulties. The booklet presents simple concepts of motor coordination planning and the consequences of disabilities in this process, addresses the physical, emotional and academic characteristics of children with DCD, and emphasizes the important role of the occupational therapist in analyzing motor skill development and determining the ability of a child to cope with the demands and activities of everyday life. The booklet also offers strategies for parents and teachers to use at home and at school (in the classroom and in physical education).

This study aims to describe the results of application of a booklet in a group of four parents of seven-year-old children identified with signs of developmental coordination disorder DCD at a school in the municipality of São Carlos, São Paulo, Brazil. The booklet discusses strategies for dealing with the difficulties resulting from DCD.

\section{Methodology}

The present report consists of the second phase of a larger study that identified seven years old children with DCD hypothesis to a municipal school in the interior of São Paulo, Brazil. It is a report of a workshop that served as a feedback to parents of children identified with the disorder. The workshops were configured as a place for reflection and sharing life experiences on the issues raised and allow for the identification of the main topics required to understand the problem (Chiesa \& Westphal, 1995).

Parents of four of the seven children identified in the school with the disorder agreed to participate in the meetings. Teachers of the identified students were also invited, but none were available to attend. Three meetings were scheduled with the participants as well.

Participated in the workshop two fathers and two mothers of seven years children identified with signs of DCD, without the presence of children; participants lived in the outskirts of the city. The workshops were scheduled simultaneously for all parents at night in the children's own school environment. The school was the place chosen for the workshop to be of easy access to parents and to have an appropriate meeting space. All of the meetings were held within the period of one month. In each meeting notes for future discussions were held. The meetings were directed by the researcher.

\section{Workshop Description}

First meeting

The activity consisted of a game in which there were two sets of cards, one with the typical characteristics in children with DCD and the other with orientations on how to manage them at home or at school. The cards with the characteristics were placed on a table and the cards with orientations were divided and given to the parents. Each parent in turn withdrew a characteristics card and read it aloud to another parent, who verified whether he 
had a matching orientation card that could be used. Researcher participation was also necessary to define the characteristics and orientations and give examples as needed. There were also blank cards on which the parents could write attitudes that they believed could help their children.

Second meeting

It was presented the booklet "Children with Developmental Coordination Disorder: At Home, at School and in the Community" and the researcher explained that its contents would be worked on during the meeting. The items of booklet involve the characteristics of DCD and the role of parents, educators and community in dealing with the children in their routine activities.

It was exposed to the parents as occurring motor coordination difficulties, from the explanation of a poster made of cardboard with a picture that shows the system of planning actions, contained in the booklet. Was used as an example the need for motor planning to climb a ladder to facilitate understanding, and parents claimed to have understood and even sometimes realize that their children have some of these difficulties (Figure 1).

Third meeting

The purpose of this activity was that parents perform motor and daily life tasks in a given time in order to reflect on the motor planning necessary for each task and the difficulties that their children could feel when performing motor activities in their daily lives. A circuit of motor activities was performed. First, each participant had to swing a hula hoop, assemble a structure using five "domino" pieces, jump hopscotch the best they could to the other side of the room, assemble a minimum of a four-piece jigsaw puzzle, skip rope six times, and tie in a shoelace (Figure 2). Each game had to be performed in a maximum of 15 seconds, and as soon as the first participant went on to the second game, the next participant started the circuit. After the activity parents were encouraged to discuss them and give testimonials about their feelings.

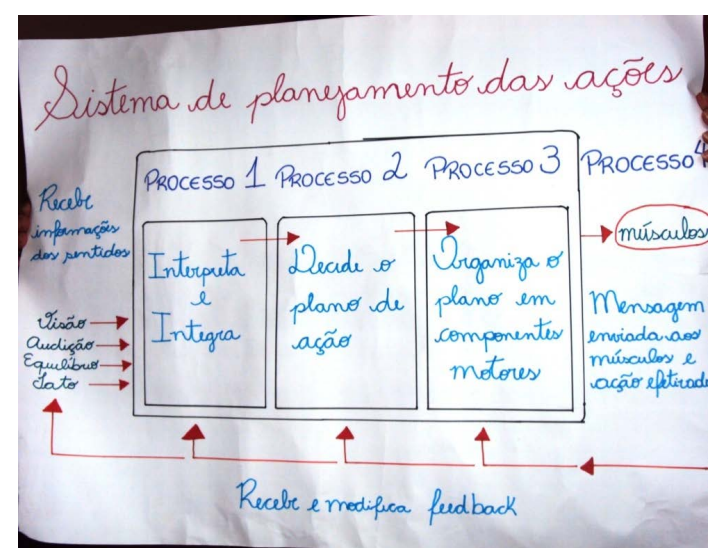

Figure 1. Explanatory framework operating system planning actions (adapted of Missiuna, Rivard, \& Pollock, 2011).

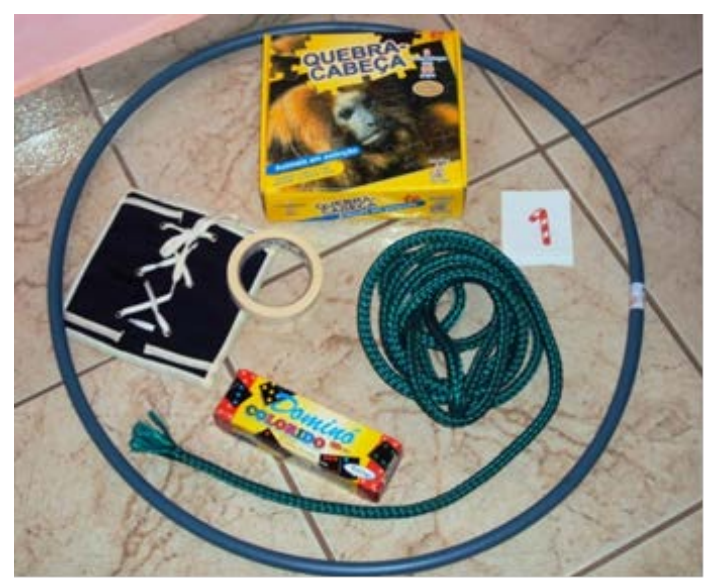

Figure 2. Toys used in the circuit. 


\section{Results}

The parents identified the characteristics mentioned in the cards to those presented by their children, especially the ones related to academic, playtime, and everyday life activities that involve motor components. However, they added nothing.

Parents actively participated in the discussion and asked questions about the disorder and about the material presented.

Mother 1 alleged that her daughter had all of the characteristics mentioned in the cards as well as more pronounced difficulties in reading and writing, focusing, physical play, and the preference to play alone. At the end of the game, the orientation topic in the booklet was reviewed and handed to the parents. Mother 1 thanked the researcher and highlighted that:

"The workshops helped me better understand my daughter's difficulties and now I believe I know how to deal with them."

The parents were involved in all games, which demonstrated their dedication despite their unfamiliarity with the games.

The parents commented on their feelings about the difficulties faced.

Mother 2 said:

"It was 'cool' to experience games that are part of my son's routine and how something that seems simple becomes difficult when we do not do it often or when there is an obligation of doing it at a certain velocity."

Father 1 agreed, saying that:

"There might still be a sense of frustration for being unable to do what is asked and the shame of being the slowest or the one that was unable to do it." (he took a long time to assemble the jigsaw puzzle)

The parents revealed the difficulty of their children, who are focused on classroom activities like slow handwriting and excessive force used when writing with a pencil as well as difficulties in daily life activities like clothing (clothes put on inside out, not being able to tie shoelaces), eating (taking too long to use a fork and knife), and playing (running, jumping, playing ball).

Afterwards, it was explained how motor coordination difficulties in children occur using a figure in the manual, a demonstrative table of the action plan system (Figure 1).

Mother 2 said she understands:

"How important the role of professionals like the occupational therapy in school is, advising parents about the difficulties of children and how they occur."

Father 2 added:

"It is very important to involve parents in the school life of their children because most of the time they might not realize the difficulties that the children face and they might even feel their hands are tied for not knowing how to act."

At the end of the workshop, time was given for questions, opinions, and suggestions. The parents thanked the researcher for visiting the school environment and providing guidance. They highlighted the belief in the importance of the University's role in projects within the schools that help parents and teachers with recent and differentiated knowledge. The booklet with the orientations was handed to the parents. At the end of the session, the parents were requested to summarize all the meetings in a single feeling. Father 1 used satisfactory and Mother 2 used hope.

\section{Discussion}

The application of the booklet "Children with Developmental Coordination Disorder: At Home, at School and in the Community" along with workshops discussed themes central to DCD such as: symptom identification, a sampling by parents of the difficulties that their children experience in their daily lives and orientations on how to understand such difficulties to help children succeed at home and at school. The activities performed with the participants were intended to help parents understand the difficulties their children related to DCD.

During the activities, the parents identified in their children typical characteristics of DCD and related to their motor coordination, such as difficulty with academic activities, slow handwriting, and inaccurate force use as well as difficulty in their everyday life activities such as dressing, eating, leisure activities, physical play, the preference for playing alone, and frustration about failure.

Attention should be drawn to the fact that during the workshops, the focus was on the characteristics per- 
ceived by the parents. It should also be highlighted that the use of the booklet together with games proved to be an important approach to working with parents on DCD. The content allows for an easy, clear, and understanding on the subject. It was possible to use it as a tool and divide it into steps to work the content in the form of workshops.

These workshops are a place for reflection and discussion of experiences that allow for the identification of the theme, combine reflection and action, and increase knowledge. It also allows the establishment of a horizontal relationship between the researcher and the participants. Simulations and activities similar to the ones faced by these children were used at the workshops, and it was possible to lead parents to reflect on the characteristics and motor and psychosocial difficulties faced by their children.

Even though the meetings were held during non-working hours, we still encountered low parent participation rates. This leads us to reflect on the need to strengthen the partnership between the school and the parents and suggests that this type of activity should be added to the activities already performed between the school and the families. The partnership between the school and families is fundamental to the success of any learning and development process. According to Fusverki \& Pabis (2008), the school should open the doors to parent participation using different activities that meet their needs. On the other hand, the lack of teacher participation in the activity is worrying and can be considered one of the limitations of the study. Provide their participation in this space to clarify doubts about the DCD is a challenge for researchers.

In this study, it was possible to understand parent identification with DCD-related problems as being similar to their children's characteristics and difficulties as well as their acknowledgment of the need for more specific attention being paid to their children's academic and everyday lives. Attention should be drawn to the fact that most parents work away from the home and spend little time with their children. Nevertheless, this situation should not interfere with their participation in school activities (Fusverki \& Pabis, 2008).

Parent participation in their children's school lives is even more important when the child shows some type of deficit. In the case of DCD, in which a child shows a low tolerance to frustration, low self-esteem and a lack of motivation in addition to the need to perform motor activities in a protected environment to be more confident when facing other children, the parent's presence is a determining factor (Missiuna et al., 2007).

This study presented a report of the implementation of strategies for understanding the DCD by a small group of parents of children aged seven years. This way, it is indicated the need to expand the study in order to apply a more detailed methodological design, with pre and post test measures that can systematize the gain of parental knowledge and changing attitudes about the disorder.

\section{Conclusion}

The present report aimed to describe the experience of meeting with parents of children identified with DCD in order to explain and discuss the characteristics and difficulties related to the disorder, through the educational resource "Children with Developmental Coordination Disorder: At Home, at School and in the community". Although the study was conducted with a small number of parents, it was considered that such initiatives were important ways to inform parents of lightweight way involved with the routine aspects of children with DCD and ways of dealing with the symptoms. It is recommended that future studies should extend this experience, with a wider sample.

\section{Acknowledgements}

We thank the parents and the school participating in the research. Also we thank the student who assisted in data collection.

\section{References}

American Psychiatric Association (2013). DSM-5-Diagnostic and Statistical Manual of Mental Disorders (5th ed.). Washington, DC: American Psychiatric Association.

Araujo, C. R. S. (2010). Efeitos da terapia motora cognitiva no desempenho de atividades de crianças com transtorno do desenvolvimento da coordenação. Dissertação de Mestrado, Belo Horizonte: Escola de Educação Física, Fisioterapia e Terapia Ocupacional-UFMG.

Chiesa, A. M., \& Westphal, M. F. (1995). A sistematização de oficinas educativas problematizadoras no contexto dos serviços públicos de saúde. Saúde em Debate, 24, 19-22. 
Fusverki, E. V., \& Pabis, N. A. (2008). A participação dos pais na escola influencia para uma melhor aprendizagem. Revista Eletrônica Lato Sensu, 3, 1-5. http://escolabjr.blogspot.com.br/2011/09/participacao-dos-pais-na-escola.html

Missiuna, C., Moll, S., King, S., King, G. et al. (2007). A Trajectory of Troubles: Parents Impressions of the Impact of Developmental Coordination Disorder. Physical \& Occupational Therapy in Pediatrics, 27, 81-101.

Missiuna, C., Rivard, L., \& Pollock, N. (2011). Crianças com Transtorno do Desenvolvimento da Coordenação: Em casa e na sala de aula e na comunidade. Canada: CanChild Centre for Childhood Disability Research, McMaster University. www.fhs.momaster.ca/canchild

Pereira, H. S., Araújo, A. P. Q. C., \& Mattos, P. (2005). Transtorno do déficit de atenção e hiperatividade (TDAH): Aspectos relacionados à comorbidade com distúrbios da atividade motora. Revista Brasileira de Saúde Materno Infantil, 5, $391-402$.

Polatajko, H. J., \& Cantin, N. (2006). Developmental Coordination Disorder (Dyspraxia): An Overview of the State of the Art. Seminars in Pediatric Neurology, 12, 250-258. http://dx.doi.org/10.1016/j.spen.2005.12.007

Silva, J. A. O., Dantas, M. T., Cattuzzo, C. W., Moreira, C. R. P., \& Souza, C. J. F. (2006). Teste MABC: aplicabilidade da lista de checagem na região sudeste do Brasil. Revista Portuguesa de Ciências do Desporto, 6, 356-361. 
Scientific Research Publishing (SCIRP) is one of the largest Open Access journal publishers. It is currently publishing more than 200 open access, online, peer-reviewed journals covering a wide range of academic disciplines. SCIRP serves the worldwide academic communities and contributes to the progress and application of science with its publication.

Other selected journals from SCIRP are listed as below. Submit your manuscript to us via either submit@scirp.org or Online Submission Portal.
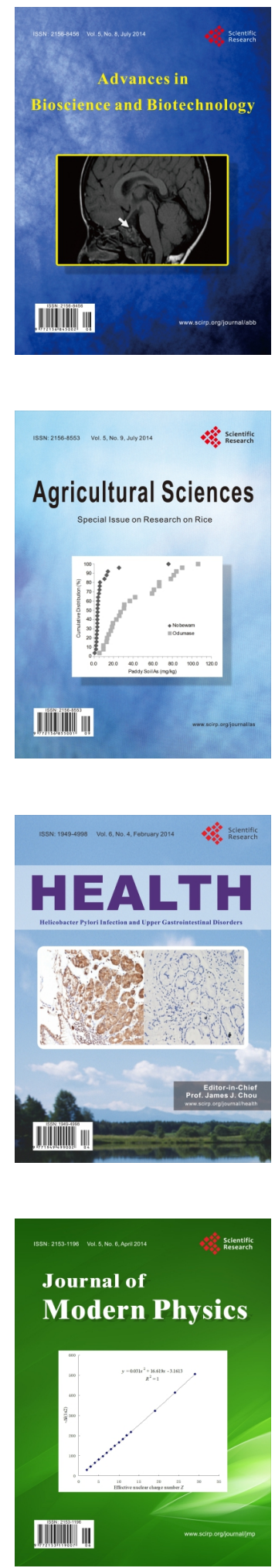
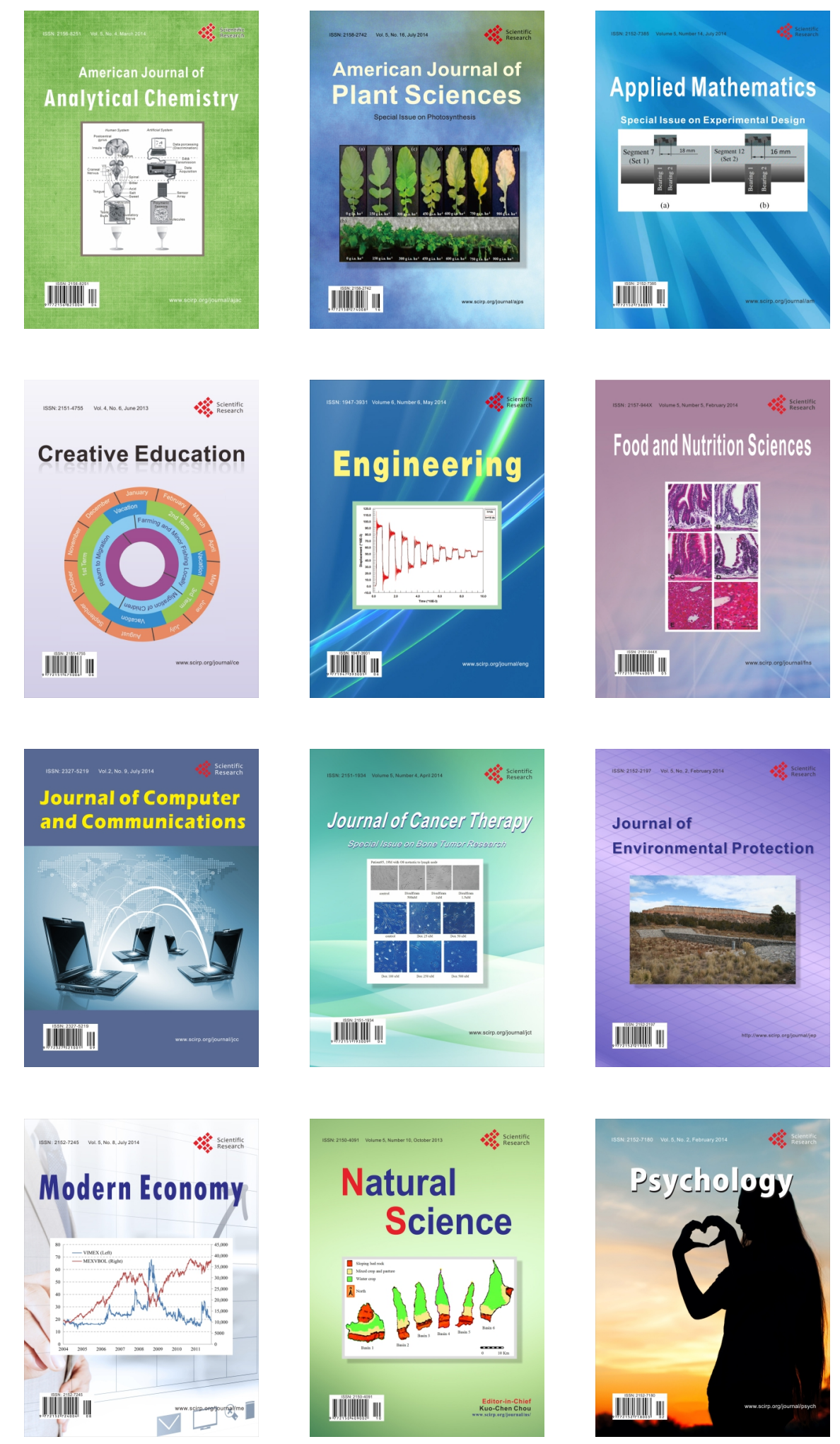